\title{
Quality of life of patients from rural and urban areas in Poland with head and neck cancer treated with radiotherapy. A study of the influence of selected socio-demographic factors
}

\author{
Adam Depta ${ }^{1,2}$, Maciej Jewczak ${ }^{3}$, Anna Skura-Madziała ${ }^{4,5}$
}

\begin{abstract}
1Department of Health Care Financing, Medical University of Lodz, Lodz, Poland ${ }^{2}$ Department of Management, Technical University of Lodz, Lodz, Poland ${ }^{3}$ Department of Spatial Econometrics, Institute of Spatial Economics, Faculty of Economics, and Sociology, University of Lodz, Lodz, Poland ${ }^{4}$ Institute of Public Health, Collegium Masoviensae, Lodz, Poland

${ }^{5}$ Regional Oncological Centre, Radiotherapy and General Oncology Ward, Nicolaus Copernicus Hospital, Lodz, Poland
\end{abstract}

Submitted: 13 July 2015

Accepted: 28 November 2015

Arch Med Sci 2017; 13, 6: 1474-1482

DOI: https://doi.org/10.5114/aoms.2017.71068

Copyright @ 2017 Termedia \& Banach

\section{Abstract}

Introduction: The quality of life ( $\mathrm{Q} o \mathrm{~L})$ experienced by cancer patients depends both on their state of health and on sociodemographic factors. Tumours in the head and neck region have a particularly adverse effect on patients psychologically and on their social functioning.

Material and methods: The study involved 121 patients receiving radiotherapy treatment for head and neck cancers. They included 72 urban and 49 rural residents. QoL was assessed using the questionnaires EORTC-QLQ-C30 and QLQ-H\&N35. The data were analysed using statistical methods: a $\chi^{2}$ test for independence and a multinomial logit model.

Results: The evaluation of QoL showed a strong, statistically significant, positive dependence on state of health, and a weak dependence on sociodemographic factors and place of residence. Evaluations of financial situation and living conditions were similar for rural and urban residents. Patients from urban areas had the greatest anxiety about deterioration of their state of health. Rural respondents were more often anxious about a worsening of their financial situation, and expressed a fear of loneliness.

Conclusions: Studying the QoL of patients with head and neck cancer provides information concerning the areas in which the disease inhibits their lives, and the extent to which it does so. It indicates conditions for the adaptation of treatment and care methods in the healthcare system which might improve the QoL of such patients. A multinomial logit model identifies the factors determining the patients' health assessment and defines the probable values of such assessment.

Key words: quality of life, head and neck cancer, sociodemographic factors, EORTC-QLQ-C30, QLQ-H\&N35: HRQoL.

\section{Introduction}

The Constitution of the World Health Organization defines health as "A state of complete physical, mental, and social well-being and not merely the absence of disease". Quality of life (QoL) is defined as "an in-

\author{
Corresponding author: \\ Adam Depta PhD \\ Department of Health \\ Care Financing \\ Medical University \\ 6 Lindleya St \\ 90-131 Lodz, Poland \\ Phone: +48 426779316 \\ Department of Management \\ Technical University \\ of Lodz \\ 266 Piotrkowska St \\ 90-924 Lodz, Poland \\ Phone: +48426313762 \\ E-mail: adam.depta@p.lodz.pl
}


dividual's perception of their own position in life, in the context of the culture and value systems in their life and in relation to their goals, expectations, standards and concerns" [1].

Advances in medical technology enable treatment of more difficult and complex cases, resulting in a systematic increase in the length of patients' lives, but attention is focused not only on longevity but also on QoL. Nowadays, QoL assessment methods are routinely used to assess the costs and benefits of different health programs and medical interventions.

One of the definitions specifies QoL as the impact of the disease on both the physical functioning and subjective level of well-being of patients [2]. Studies on QoL aim to answer the general question to what extent the consequences of the illness and the applied treatment may - despite improving physical well-being - influence deterioration of the way patients function in given living conditions [3]. Schipper introduced the concept of health-related quality of life (HRQoL) [4].

Assessment of the QoL after therapy is especially important in the case of people who have been diagnosed with head and neck squamous cancer (HNSC). The tumours often cause visible deformations of the head, skull and neck, and their location significantly affects performance of basic activities.

The main factor leading to the formation of squamous cell head and neck cancers is carcinogens included in nicotine. Other risk factors of this disease are alcohol, poor oral hygiene and mechanical irritation of the mucous membranes (e.g. by an incorrectly fitted dental prosthesis). Another cause of some head and neck cancers is Epstein-Barr or human papilloma virus infection (HPV) [5]. Research is also being carried out to determine the genetic background of human vulnerability to developing squamous cell cancer of the head and neck [6].

Because these tumours are located in the upper part of the digestive and respiratory systems (mouth, pharynx, larynx, nasal cavity, salivary glands and nasal sinus), usually some serious physical ailments that hinder vital functions occur simultaneously. Patients struggle with respiratory, nutrition and speech problems. Often patients suffer from impairment of sight, hearing, smell or taste. Any distortion and functional defects caused by the disease itself and its treatment result in negative psychological and social effects for the patients [7].

Radiotherapy, next to surgery, is a routine method of treatment for early stage HNSC. Radiotherapy (RT) used as a form of therapy is also associated with the occurrence of side effects, influencing the patients' QoL [8]. The effects of the disease itself and its treatment destructively affect daily activities, reducing both physical and functional performance, decreasing physical, functional and emotional abilities [9]. Patients have an acute sense of stress, and experience physical pain of varied intensity. The results of research indicated that RT significantly and negatively influences the QoL of patients with HNSCC, when comparing the end of the RT course initial parameters [10].

Measurement of the QoL of patients with head and neck cancer is generally difficult and laborious, but doing so could simplify choosing the best treatment option. According to Rogers, the main difficulties arise from the following situations: different location and degree of the clinical stage of cancer, various treatment methods and questionnaires used in the evaluation process. Other factors that make it difficult to assess the QoL are concomitant comorbidity, the patient's personality and cultural differences [11]. Culture and language specific measuring tools are needed for any given group of patients, e.g. validation of the Polish version of the questionnaires [12, 13].

The study involved the following sociodemographic factors: date of birth, sex, place of residence, employment and financial status, type of workplace, noticeable symptoms of anxiety, family and social support, housing, and assessment of health status after radiotherapy.

\section{Material and methods}

A prospective study was conducted for a group of patients with histologically confirmed, primary HNSC, who underwent RT alone or radiochemotherapy (RT-CT). The research group consisted of 121 patients (82 males, 39 females) treated at the Regional Oncological Centre in the Radiotherapy and General Oncology Ward of the Nicolaus Copernicus Hospital in Lodz: 72 of all patients lived in a city, the remainder in rural areas. The duration of radiation treatment was from 2 to 6 weeks, depending on the severity of the cancer. A survey by questionnaire was carried out from November 2013 to June 2014. The age range of patients by date of birth was 1927-1990 (Tables I-III).

In the study, for the purpose of QoL evaluation, the standardized EORTC-QLQ-C30 (The EORTC QLQ - PRT23 questionnaire (European Organization for Research and Treatment of Cancer) "An International Field Study of the Reliability and Validity of a Proctitis Specific Quality of Life Module"; certificate issued on 9 July 2012, by the Western Australian Centre for Cancer and Palliative Care, Faculty of Health Sciences, Curtin Health Innovation Research Institute, GPO Box U1987, Perth Western Australia 6845) questionnaire (ver. 3.0) and for the study specific symptoms related to 
Table I. Evaluation of housing conditions and their similarity among respondents by place of residence

\begin{tabular}{|lccc|}
\hline $\begin{array}{l}\text { Housing } \\
\text { conditions }\end{array}$ & $\begin{array}{c}\text { Urban area } \\
(\%)\end{array}$ & $\begin{array}{c}\text { Rural area } \\
(\%)\end{array}$ & $\begin{array}{c}\text { Similarity } \\
\text { index (\%) }\end{array}$ \\
\hline Very good & 21.43 & 22.73 & 21.43 \\
\hline Good & 60.71 & 60.61 & 60.61 \\
\hline Poor & 17.86 & 13.64 & 13.64 \\
\hline Appalling & 0.00 & 3.03 & 0.00 \\
\hline Total & & \multicolumn{3}{c}{95.67} \\
\hline
\end{tabular}

Table II. Assessment of the financial situation and its similarities among the respondents by place of residence

\begin{tabular}{|lccc|}
\hline $\begin{array}{l}\text { Material } \\
\text { situation }\end{array}$ & $\begin{array}{c}\text { Urban area } \\
(\%)\end{array}$ & $\begin{array}{c}\text { Rural area } \\
(\%)\end{array}$ & $\begin{array}{c}\text { Similarity } \\
\text { index (\%) }\end{array}$ \\
\hline Very good & 14.29 & 4.55 & 4.55 \\
\hline Good & 21.43 & 25.76 & 21.43 \\
\hline Mediocre & 50.00 & 56.06 & 50.00 \\
\hline Poor & 10.71 & 9.09 & 9.09 \\
\hline Appalling & 3.57 & 4.55 & 3.57 \\
\hline Total & & & 88.64 \\
\hline
\end{tabular}

Table III. Ratings of the respondents' QoL by place of residence

\begin{tabular}{|lcc|}
\hline Quality of life levels & Urban area (\%) & Rural area (\%) \\
\hline 1 & 1.82 & 4.55 \\
\hline 2 & 7.27 & 9.09 \\
\hline 3 & 27.27 & 22.73 \\
\hline 4 & 29.09 & 33.33 \\
\hline 5 & 21.82 & 16.67 \\
\hline 6 & 10.91 & 7.58 \\
\hline 7 & 1.82 & 6.06 \\
\hline
\end{tabular}

Seven-scaled rating, where level 1 is the worst and 7 is the best.

head and neck cancers and their treatment, the data were collected on the basis of the EORTC QLQ-H\&N3 (Questionnaire Quality of Life, module for Head and Neck Cancer) questionnaire.

Patients completed the questionnaire once at the end of the course of radiotherapy. They completed questionnaires independently and in case of any difficulties in understanding the questions they benefited from the help of the research staff or family members. The questionnaires were analysed statistically according to the guidelines of the EORTC.

The EORTC QLQ-C30 is a QoL questionnaire that is filled out individually and evaluates many aspects of QoL of cancer patients. The question- naire consists of several questions divided into: a) five functional scales (physical, role, emotional, cognitive and social - expressed on a 4-point Likert scale); b) one global QoL category (expressed on a 7-point Likert scale); c) three scales of symptoms (fatigue, nausea/vomiting, pain); d) six individual elements (expressed on a 4-point Likert scale). The further rating is expressed on a scale ranging from 0 to 100 points. For functional and global QoL scales, a higher score indicates a higher level of functioning and overall QoL. For observed symptoms and scales of individual elements, a high score indicates a more severe impact of the symptoms or problems.

The EORTC QLQ-H\&N35 questionnaire consists of 35 items designed in such an order as to assess health-related QoL and contains seven measurement scales (pain, swallowing, senses, speech, eating, social contact and sexuality) and 11 individual elements regarding problems with teeth, opening the mouth, dryness of mouth, sticky saliva, cough, malaise, pain medications, supplements, feeding tubes, and change in body weight. Most of the questions in this questionnaire are expressed on a 4-point Likert scale, and here a higher value indicates a lower level of QoL.

Attainment of the article's objectives requires implementation of probability techniques, for more than just bivariate categories. To examine the probability of respondents'/patients' health status, the multinomial logit modelling approach was used [14]. Respondents could specify their health on a 5-level gradual scale of health status (from bad, through good to perfect health). It was impossible to assess the likelihood ratios of a given health state in a typical, binary logit approach; hence the multinomial approach was used. Evaluation of the multinomial logit model requires prior data standardization. A reference point (base category) for interpretation of the parameters of each category must be defined. In this analysis, "poor" health status was adopted as the base category.

Estimation of a multinomial logit model is performed by the maximum likelihood method that allows the use of Wald test statistics to establish the significance of the model's structural parameters. Evaluation of the quality of the model, as in the binary logit version, is possible on the basis of McFadden's pseudo- $R^{2}$.

The most important issue in the construction of the econometric model is to identify exogenous variables affecting the endogenous category. In order to determine the factors that may influence the assessment of the health status of respondents, multiple dependence tests were conducted. The dependence of the characteristics was examined with the $\chi^{2}$ test of independence, and the 


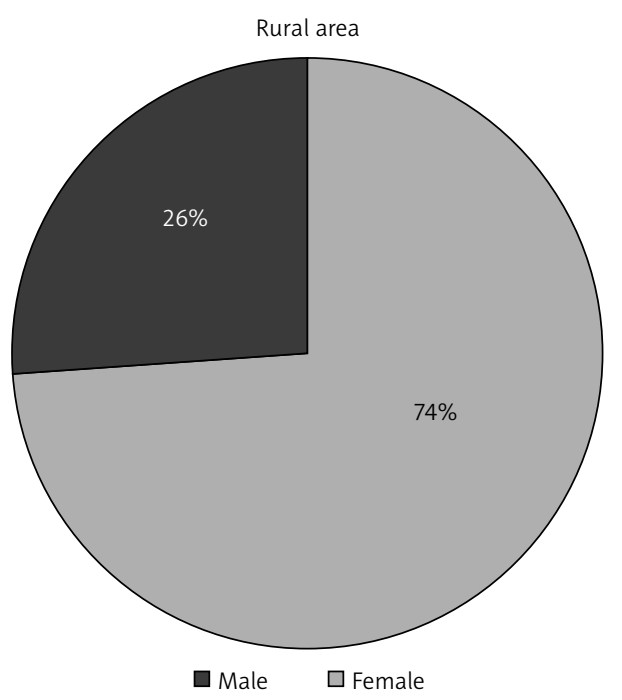

Figure 1. Respondents by gender and place of residence

strength of the relationship was studied on the basis of results of Pearson's contingency coefficient $C$. The necessary analyses were performed using SPSS statistical package ver. 21.0.

After analysing independency, valuable information was obtained, which indicated that the degree of patients' health status assessment is not a function of characteristics such as age, sex, or place of residence. The initial results also indicated that the level of health assessment may be determined by an assessment of the QoL of the respondents, physical abilities, perceived pain and concerns about their appearance, or a respondent's employment status. The variables were selected accordingly from the database and used in the construction of a multinomial logit model.

\section{Statistical analysis}

EORTC QLQ-C30 and QLQ-H\&N35 questionnaires were drawn up statistically according to the ESTRO guidelines. For constructing and estimating parameters of multinomial logit models (MNL) Statistical Package for the Social Sciences (SPSS 21.0) was used. Data was initially normalized, and the reference point was created - as the base category "poor" health status was assumed. A set of mutually exclusive possibilities (various health statuses) was formulated, allowing constructing the 4-equational MNL model. Model's exogenous variables (those which could determine the assessment of the health status) were selected on the basis of multiple $\chi^{2}$ independence tests, followed by the analysis of C-Pearson's contingency coefficients. To establish the significance of the model's structural parameters, maximum likelihood method and Wald's test statistics were adopted. In both cases $p$-value of less than 0.05 was considered to be statistically significant. The model's goodness of fit was investigated with Mc-

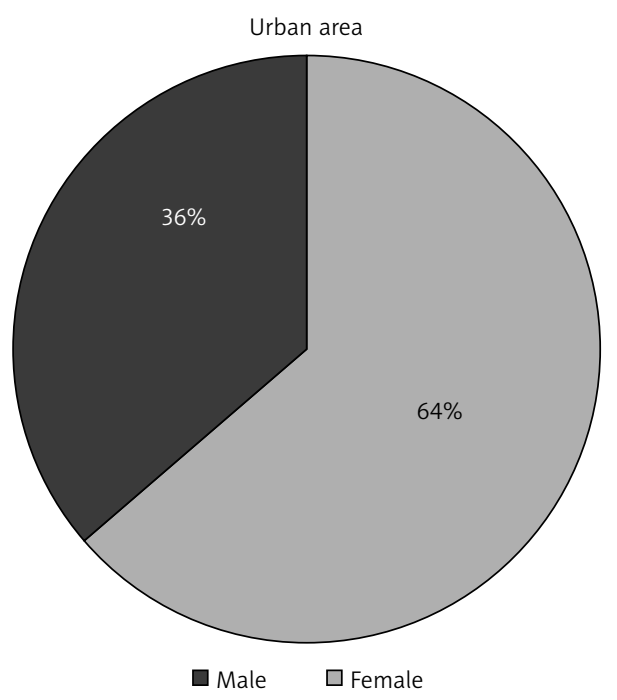

Fadden's pseudo- $R^{2}$. The values of MNL model's parameters represented the odds ratios for factors that influenced being in exact, different from "poor" health status.

\section{Results}

The research group consisted of 121 patients (82 males and 39 females) treated with radiotherapy for head and neck cancers. The majority of the respondents (72 of them) lived in a city, whereas the rest (49) lived in rural areas (Figure 1). The initial estimates below were conducted in such a way as to compare respondents from different places of residence.

The survey data showed that most of the cancer patients were not looking for employment, and only one in five had paid employment (Figure 2). However, when comparing patients from rural areas to those from the urban areas, people from the countryside more often were looking for a job.

Patients admitted that they were facing many worries. From the point of view of an individual - the sick person - it was not surprising that

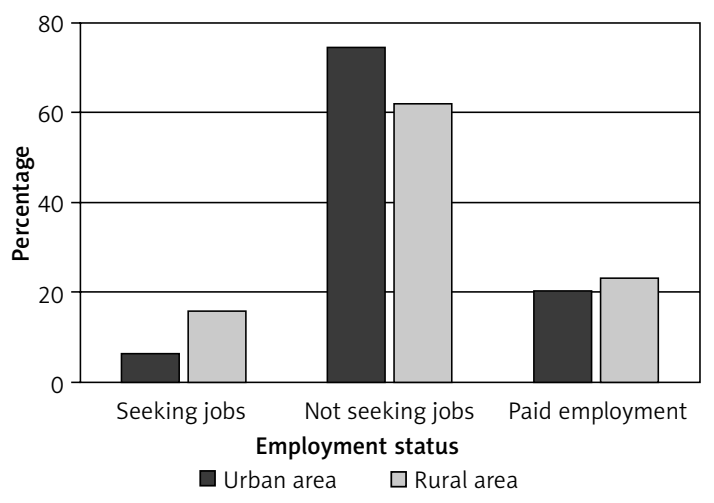

Figure 2. Respondents' employment status by place of residence 


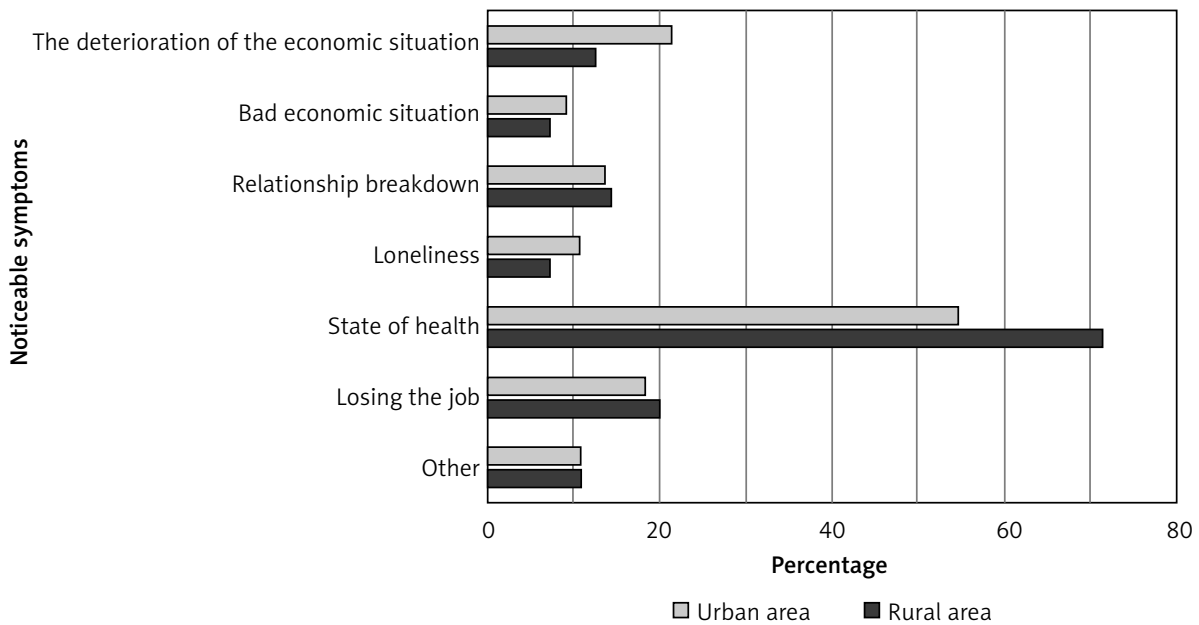

Figure 3. Respondents' perceptible concerns by place of residence

most people expressed concerns associated with their medical condition (Figure 3). It should be emphasized that more people from urban rather than from rural areas felt concerns for their health. In the countryside, respondents were afraid of deterioration of their financial situation, or loneliness.

Most of the respondents, regardless of the place of residence, assessed their housing conditions as "good". Comparing the structures of these characteristics, by place of living, a strong resemblance was obtained - the index value indicated a $95.67 \%$ level of similarity of the structures' distributions. Every fifth respondent rated their housing conditions as "very good" (Table IV). Individuals whose living conditions were very poor accounted for a minority in the study - for those from a city there were no such cases.

A similarity was also found for the assessment of the financial situation. Most frequently the apparent subjective assessment of one's financial situation was at a mediocre level (Table V). Very similar proportions of respondents defined their financial situation as poor or appalling. The greatest disproportion was noticeable for "very good" financial situation - only $5 \%$ of patients in rural areas considered themselves as well-off, whereas in the cities this percentage was three times higher. The structure of the characteristics by place of residence also showed a strong resemblance - the index value indicated a $88.64 \%$ level of similarity of structures.
Table IV. Pearson's correlation coefficient in the assessment of health status and QoL

\begin{tabular}{|lcc|}
\hline & Health state & Quality of life \\
\hline Health state & 1 & $0.804^{* *}$ \\
\hline Quality of life & $0.804^{* *}$ & 1 \\
\hline
\end{tabular}

${ }^{* \star}$ Correlation is significant at the level of 0.01 (two-sided).

The survey data also provided information on the health status and evaluation of life of people suffering from cancer. Those who described their health as "very good" were in a minority (Figure 4). The most frequent response was the average rating of their health condition. A poor assessment of health state most often characterised people living in cities rather than in rural areas. Similarities were also observed between groups of people reporting good health status.

As far as the assessment of QoL is concerned, respondents living in rural areas evaluated more their quality of life in the worst categories. Among the midpoints, the ratings distributions of the respondents' answers were quite similar, with a slight predominance of people living in urban areas. However, in the study, people living in rural areas could be more often at the "best" level of subjective QoL (Table VI).

A test based on chi-square $\left(\chi^{2}\right)$ statistics was used to investigate the dependencies between place of residence, health status and QoL. In each case, the test of independence did not indi-

Table V. Fit of the proposed multinomial logit model

\begin{tabular}{|lcccccc|}
\hline Model & Model fit criterion & \multicolumn{3}{c}{ Likelihood ratio test } & & Pseudo- $R^{2}$ \\
\hline & -2 log-likelihood & $\chi^{2}$ & $\mathrm{~d} f$ & Significance & Cox and Snell & 0.262 \\
\hline Base & 169.197 & 37.145 & 8 & $<0.001$ & Nagelkerke & 0.283 \\
\cline { 1 - 2 } & 132.052 & & & & McFadden & 0.116 \\
\hline
\end{tabular}


cate the existence of relationships between the analysed categories. Statistical significance was found for evaluations based on health status and QoL (Table VII) - verification was performed with the independence test. The results showed statistical significance of the relationship between characteristics, and due to the fact that both variables were noted on a quotient scale, to examine the strength and direction of dependency Pearson's correlation coefficients with statistical verification of their significance were determined.

To examine the probability of the occurrence of certain health statuses the multinomial logit modelling approach was used. The first stage after the construction of the multinomial logit model with specified exogenous variables was verification of the model's relevance. For this purpose, the criterion of model fit was assumed and the summary results of the likelihood ratio $\chi^{2}$ test are presented below (Table VIII).

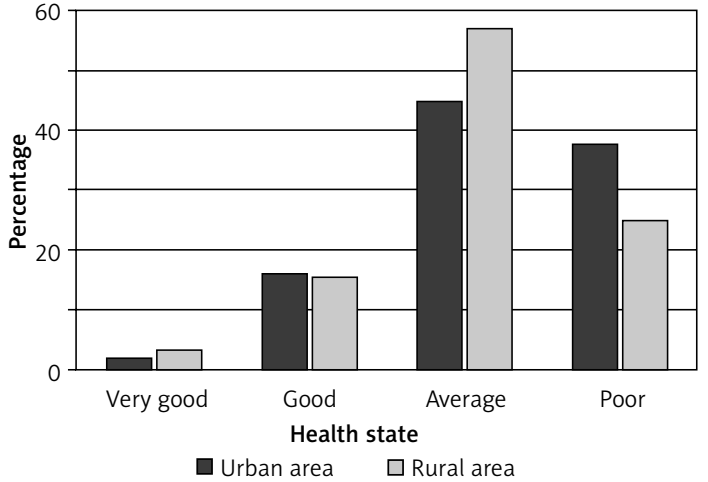

Figure 4. Respondents' health state assessment by place of residence

Testing statistics for the final model (compared to the base model) indicated that in terms of the model quality (reliability relevance test significance is lower than the expected level of significance $\alpha=0.05$ ) the final model outperformed

Table VI. Estimation results of the multinomial logit model for the assessment of health status

\begin{tabular}{|c|c|c|c|c|c|c|}
\hline \multicolumn{2}{|c|}{ In general your health status is... } & \multirow{2}{*}{$\begin{array}{c}\text { B } \\
-4.581\end{array}$} & \multirow[t]{2}{*}{$\operatorname{Exp}(B)$} & \multirow{2}{*}{$\begin{array}{c}\text { Standard error } \\
3.087\end{array}$} & \multirow{2}{*}{$\begin{array}{l}\text { Wald } \\
2.203\end{array}$} & \multirow{2}{*}{$\begin{array}{c}\text { Significance } \\
0.138\end{array}$} \\
\hline Excellent & Const & & & & & \\
\hline & P3 & -0.371 & 0.690 & 0.848 & 0.191 & 0.662 \\
\hline & P30 & 0.823 & 2.277 & 0.521 & 2.495 & 0.114 \\
\hline \multirow[t]{3}{*}{ Very good } & Const & -0.927 & & 1.803 & 0.264 & 0.607 \\
\hline & P3 & -0.449 & 0.638 & 0.534 & 0.707 & 0.400 \\
\hline & P30 & 0.218 & 1.244 & 0.355 & 0.379 & 0.538 \\
\hline \multirow[t]{3}{*}{ Good } & Const & 0.004 & & 1.367 & 0.000 & 0.997 \\
\hline & P3 & -1.579 & 0.206 & 0.484 & 10.643 & 0.001 \\
\hline & P30 & 0.757 & 2.132 & 0.264 & 8.244 & 0.004 \\
\hline \multirow[t]{3}{*}{ Not so good } & Const & 2.048 & & 1.144 & 3.207 & 0.073 \\
\hline & P3 & -0.924 & 0.397 & 0.354 & 6.796 & 0.009 \\
\hline & P30 & 0.119 & 1.126 & 0.231 & 0.265 & 0.607 \\
\hline
\end{tabular}

${ }^{a}$ Base category is the poor health state. P3 - difficulties while taking a short stroll away from home, P30 - evaluation of QoL.

Table VII. Classification of cases for a given model

\begin{tabular}{|c|c|c|c|c|c|c|}
\hline \multirow[t]{2}{*}{ Observed values } & \multicolumn{6}{|c|}{ Predicted values } \\
\hline & Excellent & Very good & Good & Not so good & Poor & Correct \% \\
\hline Excellent & 0 & 0 & 1 & 2 & 0 & 0.0 \\
\hline Very good & 0 & 0 & 2 & 5 & 1 & 0.0 \\
\hline Good & 0 & 0 & 21 & 16 & 2 & 53.8 \\
\hline Not so good & 0 & 0 & 10 & 38 & 2 & 76.0 \\
\hline Poor & 0 & 0 & 0 & 14 & 8 & 36.4 \\
\hline Overall \% & 0.0 & 0.0 & 27.9 & 61.5 & 10.7 & 54.9 \\
\hline
\end{tabular}


Table VIII. Patients' cancer location

\begin{tabular}{|lc|}
\hline Cance r's location & Number of cases \\
\hline Larynx & 24 \\
\hline Sublingual gland & 18 \\
\hline Tongue & 10 \\
\hline Mouth floor & 9 \\
\hline Oral cavity & \\
\hline Pharynx & 8 \\
\hline Lip & 5 \\
\hline Pyriform sinus & 4 \\
\hline Oropharynx & 3 \\
\hline Palatine tonsil & \\
\hline Nasopharynx & 2 \\
\hline Olfactory neuroblastoma & \\
\hline Nasal cavity & \\
\hline Thyroid gland & \\
\hline Maxillary sinus & \\
\hline Laryngopharynx & \\
\hline Palate & \\
\hline Paranasal sinuses & \\
\hline No reply & \\
\hline & \\
\hline
\end{tabular}

the base model consisting of the constant only. McFadden's pseudo- $R^{2}$ was 0.116 , which showed that the introduction of the exogenous variables into the model improved the matching probability for data. Interpretation of the model's parameters (Table IX) should be conducted in reference to the base category - "poor" health status.

Taking into account the values of the variable for good health assessment (P30) $\beta_{32}=0.757$ (exp$\left.\left(\beta_{32}\right)=2.132\right)$, the parameter indicated that the odds ratio is equal to 1.132 . This means that if the level of subjective QoL increased by unity, the probability assessment of the health as "good" in relation to the base category would increase by approximately $113.2 \%$, ceteris paribus. Similarly, when physical exercise, such as a short stroll, results in a higher perceived level of difficulty, the probability assessment of health status as "good" in relation to the base category should decrease by $80 \%$, ceteris paribus.

The model correctly classified $54.9 \%$ of cases: it performed "the worst" for the state of health: "excellent" and "very good" ( $0 \%$ correct classification). The "best" performance was for "not so good" health state (76\% correct classification) and "good" health condition (53.8\% correct classification). Assuming that the values of the independent variables (P3 and P30) would be adopted at an average level, it was possible to state (for those
Table IX. Patients' other comorbidities

\begin{tabular}{|lc|}
\hline The name of the disease & Number of cases \\
\hline Hypertension & 20 \\
\hline $\begin{array}{l}\text { Enlarged and tortuous } \\
\text { VEINS }\end{array}$ & 10 \\
\hline Asthma, bronchial & 4 \\
\hline Apoplexy & 3 \\
\hline Myocardial ischemia & \\
\hline Diabetes mellitus & \\
\hline Thrombosis & 2 \\
\hline Asthma, occupational & 1 \\
\hline Hyperthyroidism & \\
\hline Liver cirrhosis & \\
\hline $\begin{array}{l}\text { Pulmonary disease, } \\
\text { chronic obstructive }\end{array}$ & \\
\hline Hemiparesis & \\
\hline Psoriasis & \\
\hline Prostatic hyperplasia & \\
\hline Umbilical hernia & \\
\hline Myocardial infarction & \\
\hline Arteriosclerosis dementia & \\
\hline Alcohol abuse, chronic & \\
\hline Overweight & \\
\hline No reply & \\
\hline
\end{tabular}

living in a city) that an individual would determine his/her health condition as "not so good" with the probability of $46.38 \%$; there is also a $16.10 \%$ chance that an individual would determine his/ her health as "poor". The probability of a respondent's being in "good" health equalled 27.52\% and in "very good" health $7.50 \%$. The smallest chance $(2.5 \%)$ occurs for individuals that would identify their health status as "perfect" (Table X).

The distribution of probabilities for assessing the health of respondents was very similarly shaped - this highlights the above statement that there were no significant differences between the average values for the independent variables according to the place of residence (Figure 5).

\section{Discussion}

In recent decades studies on the QoL have become increasingly important for oncology, including in the case of tumours located in the head and neck area [15]. Patients' QoL assessment may be applied in clinical practice as it provides information on the individual or social context. Seeing the illness from the patient's perspective and learning from the patient's subjective opinions, 
needs, problems and priorities during treatment contributes to increasing the quality of medical care. It may also influence the choice of therapeutic methods in clinical practice and the change of health care strategy on a larger scale [16].

De Boer et al. and Nagy et al. confirmed that the effects of the HNSC treatment (such as specialist rehabilitation, plastic surgery) have a significant impact on the QoL of patients [17, 18]. According to Velden et al. adequate social support in diagnosis can have a positive impact on HRQoL during the treatment of patients with HNSC and after completion. Identifying patients at risk for poor QoL depends directly on the health (HRQoL) and further allows development of methods and measures to support this group [19].

Howren et al. proved that social and psychosocial support enhances the effectiveness of the treatment and positively correlates with QoL and survival after surgery and radiotherapy [20]. Sehlen et al. emphasized that only sociodemographic variables predict QoL after RT for HNSC patients. Early specific support from radiotherapy personnel, during the disease-coping process as well as the rehabilitation, should be a permanent component of an integrated radio oncological treatment schedule. Social support is rated high and remained constant over the treatment period [21].

The conducted study for oncology patients from different areas of residence showed that the main factors determining the subjective evaluation of QoL was good health, which could be directly associated with feeling of a higher QoL, and a lack of concerns about financial status.

The study also revealed weaker aspects of health care in Poland: low social and financial sup-
Table X. Patients' age during radiotherapy

\begin{tabular}{|c|c|}
\hline Patient's age & Number of cases \\
\hline 87 & 1 \\
\hline 82 & \\
\hline 77 & \\
\hline 76 & \\
\hline 75 & 2 \\
\hline 74 & \\
\hline 66 & 16 \\
\hline 63 & 13 \\
\hline 62 & 10 \\
\hline 61 & 9 \\
\hline 60 & 8 \\
\hline 56 & \\
\hline 55 & 7 \\
\hline 54 & 3 \\
\hline 53 & \\
\hline 50 & \\
\hline 45 & 2 \\
\hline 44 & \\
\hline 40 & 1 \\
\hline 38 & \\
\hline 29 & \\
\hline 24 & \\
\hline No reply & 15 \\
\hline
\end{tabular}

The probability of assessing the health for average values of the independent variables for rural areas

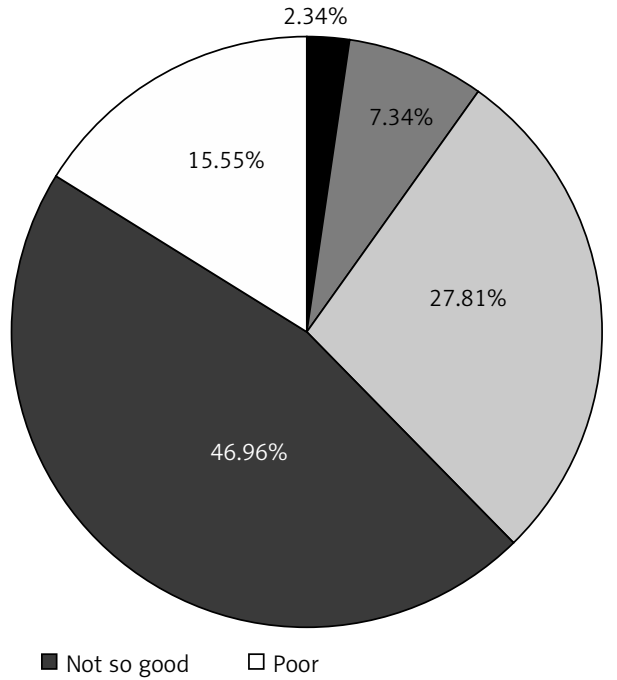

Figure 5. Probability distribution of the respondents by place of residence 
port, anxiety about poverty and loneliness caused by the disease.

Patients from the country more frequently were looking for employment at the same time, feeling concerns about the deterioration of their financial situation. Cancer poses a threat that they might deteriorate instantly. This reflects the weak support from social welfare and the lack of psychological support for the sick.

Oniszczenko and Laskowska suggested that the destructive style of coping with the disease and high emotional reactivity may contribute to the symptoms of trauma in cancer patients [22].

The present study indicated insignificant differences in the assessment of the health state and QoL for patients in rural and urban areas. However, it was possible to determine a statistically significant positive correlation for the assessment of health status and QoL.

It is quite difficult to find examples in the literature of the use of multinomial logit modelling in health care. These techniques, however, demonstrate its usefulness especially in health insurance [23]. As was shown in the analysis, apart from identifying the factors determining the evaluation of health status, these techniques also offer the possibility of determining the probable value of the assessment of the health status of the patient.

In conclusions, the study of HNSC patients using the EORTC questionnaires contributes to the expansion of knowledge in the area of the influence of the illness and treatment method on the subjective QoL assessment. It was not confirmed that the level of health assessment differed according to place of residence. This could be indicated by the levels of the logit model probabilities, as well as the assessment of housing conditions or employment status. Moreover, statistical analysis proved the existence of dependence between the QoL and health status.

\section{Conflict of interest}

The authors declare no conflict of interest.

\section{References}

1. WHO. Handbook of basic documents. ed. 5. Palais des Nations; Geneva;1952: 3-20. WHOQoL. Measuring Quality of Life. The World Health Organization Quality of Life Instruments 1997.

2. Michalos AC. Social indicators research and health-related quality of life research. Soc Indic Res 2004; 65: 27-72.

3. Higginson IJ, Carr AJ. Measuring quality of life - using quality of life measures in the clinical setting. $\mathrm{Br}$ Med J 2001; 322: 1297-300.

4. Schipper H. Quality of life: principles of the clinical paradigm. J Psychosoc Oncol 1990; 9: 171-85.

5. Gliński B, Ząbek M, Urbański J. Basic procedures of conduct with head and neck planoepithelliale carcinoma patients. Contemp Oncol (Pozn) 2006; 6: 263-7.
6. Galbiatti ALS, Ruiz MT, Raposo LS, Maniglia JV, Pavarino-Bertelli EC, Goloni-Bertello EM. The association between CBS844ins68 polymorphism and head and neck cell carcinoma risk - a case - control analysis. Arch Med Sci 2010; 6: 772-9.

7. Baile W, Gibertini M, Scott L. Depression and tumor stage in cancer of the head and neck. Psychooncology 1992; 1: 15-24.

8. Sehlen S, Hollenhorst H, Schymura B, et al. Radiotherapy - impact of quality of life and need for psychological care: results of a longitudinal study. Onkologie 2000; 23 : 565-70.

9. Verdonck-de Leeuw IM, Buffart LM, Heymans MW, et al. The course of health-related quality of life in head and neck cancer patients treated with chemo-radiation: a prospective cohort study. Radiother Oncol 2014; 110 : 422-8.

10. Żmijewska-Tomczak M, Milecki P, Olek-Hrab K, et al. Factors influencing quality of life in patients during radiotherapy for head and neck cancer. Arch Med Sci 2014; 10: 1153-9.

11. Rogers SN. Quality of life for head and neck cancer patients - has treatment planning altered? Oral Oncol 2009; 45: 435-9.

12. Dudzińska M, Tarach JS, Burroughs TE, et al. Validiation of the Polish version of Diabetes Quality of Life - Brief Clinical Inventory (DQL-BCI) among patients with type 2 diabetes. Arch Med Sci 2014; 10: 891-8.

13. Watrowski R, Rohde A. Validiation of the Polish version of the Hospital Anxiety and Depression Scale in three populations of gynecologic patients. Arch Med Sci 2014; 10: $517-24$

14. Microeconometrics. Models and Methods of Individual Data Analysis. Gruszczyński M (ed.). Oficyna a Wolters Kluwer business, Warsaw 2010.

15. Osoba D. Lessons learned from measuring health-related quality of life in oncology. J Clin Oncol 1994; 12: 608-16.

16. Denis LJ, Roobol M, Dourcy-Belle-Rose B. Prostate cancer from the horizon of the patient. Acta Onkol 2011; 50 Suppl 1: 148-54.

17. De Boer MP, Pruyn JFA, Van den Borne HW, et al. Rehabilitation outcomes of long-term survivors treated for head and neck cancer. Head Neck 1995; 17: 503-15.

18. Nagy J, Braunitzer G, Antal M, Berkovits C, Novak P, Nagy K. Quality of life in head and neck cancer patients after tumor therapy and subsequent rehabilitation: an exploratory study. Qual Life Res 2014; 23: 135-43.

19. Velden LA, Boer M, Ledeboer QC. Physical and psychosocial correlates of head and neck cancer: an update of the literature and challenges for the future (19962003). Clin Otolaryngol 2005; 30: 303-19.

20. Howren M, Bryant Christensen, Alan J, et al. Influence of pretreatment social support on health-related quality of life in head and neck cancer survivors: results from a prospective study. Head Neck Cancer 2013; 35: 779-87.

21. Sehlen S, Hollenhorst H, Lenk M, et al. Only sociodemographic variables predict quality of life after radiotherapy in patients with head and neck cancer. Int J Radiat Oncol Biol Phys 2002; 52: 779-83.

22. Oniszczenko W, Laskowska A. Emotional reactivity, coping style and cancer trauma symptoms. Arch Med Sci 2014; 10: 110-6.

23. Jewczak M. Spatial diversity of willingness to pay for health services of households in Poland. Acta Univ Lodz Folia Oecon 2014; 3: 241-51. 